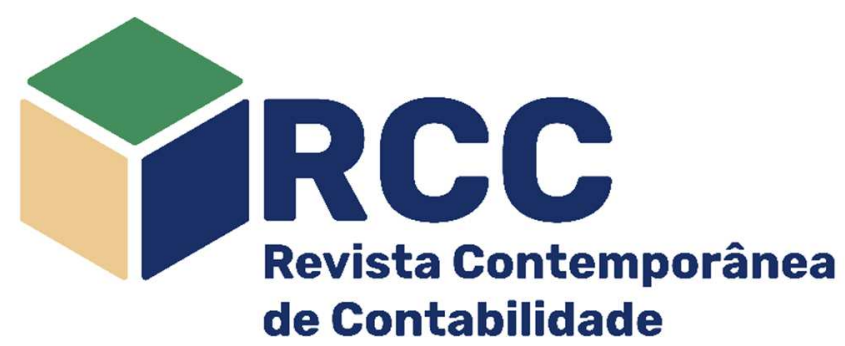

\title{
Taxa de imposto efetiva nas empresas brasileiras: uma comparação entre as companhias abertas e fechadas
}

\author{
Effective tax rate in Brazilian companies: a comparison between open and closed companies

\section{Tasa de impuesto efectiva en las empresas brasileñas: una comparación entre las compañías} \\ abiertas y cerradas
}

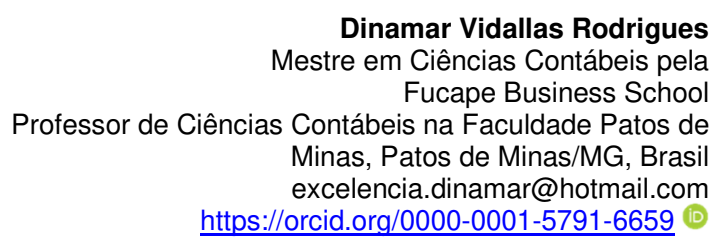

\author{
Fernando Caio Galdi* \\ Doutor em Ciências Contábeis (USP) \\ Professor Titular na Fucape Business School, \\ Vitória/ES, Brasil \\ fernando.galdi@fucape.br \\ https://orcid.org/0000-0001-6231-0010 (1)
}

Endereço do contato principal para correspondência*
Av. Fernando Ferrari, 1358 - Boa Vista, CEP: 29075-505 - Vitória, ES, Brasil

\begin{abstract}
Resumo
O objetivo desta pesquisa é investigar se há diferenças entre agressividade fiscal medida pela taxa de imposto efetiva (ETR) entre empresas de capital aberto e fechado no Brasil. A amostra é composta pelas 500 maiores empresas de capital aberto e 498 maiores empresas de capital fechado entre os anos de 2010 a 2015. Os resultados apontam que há diferença de ETR entre as empresas fechadas e as de capital aberto, indicando que as empresas fechadas possuem ETR maior, mesmo quando se controla por auditoria, intensidade de capital, estoque, alavancagem, rentabilidade e tamanho. Este resultado é de interesse para autoridades fiscais e gestores tributários, pois evidencia que as companhias abertas possuem uma gestão tributária que resulta em menores taxas efetivas de pagamento de impostos quando comparadas às empresas fechadas Palavras chave: Taxa de Imposto Efetiva; ETR; Companhias Fechadas; Companhias Abertas; Agressividade Fiscal
\end{abstract}

\begin{abstract}
This paper investigates whether there are differences between the tax aggressiveness measured by the effective tax rate (ETR) between public-held and private-held companies in Brazil. The sample consists of the 500 largest public-held companies and 498 largest private-held companies between 2010 and 2015. The results indicate that there is a difference in ETR between private and public companies, indicating that private companies have a higher ETR, even when controlled by audit, capital intensity, inventory, leverage, profitability and size. This result is of interest to tax authorities and tax managers, as it shows that publicly traded companies have tax management that results in lower effective tax payment rates.
\end{abstract}

Keywords: Effective Tax Rate; ETR; Private Companies; Public Companies; Fiscal Aggressiveness

\section{Resumen}

El objetivo de esta investigación es investigar si existen diferencias entre la agresividad fiscal medida por la tasa impositiva efectiva (ETR) entre las empresas que cotizan en bolsa y cerradas en Brasil. La muestra está compuesta por las 500 compañías más grandes que cotizan en bolsa y 498 compañías más grandes que cotizan en bolsa entre los años 2010 a 2015. Los resultados indican que existe una diferencia en ETR entre las compañías privadas y las que cotizan en bolsa, lo que indica que las compañías privadas tienen Mayor ETR, incluso cuando está controlado por auditoría, intensidad de capital, inventario, apalancamiento, rentabilidad y tamaño. Este resultado es de interés para las autoridades fiscales y los gerentes de impuestos, ya que muestra que las empresas que cotizan en bolsa tienen una gestión fiscal que resulta en tasas de pago 
de impuestos efectivas más bajas.

Palabras clave: Tasa de Impuesto Efectivo; ETR; Compañías Cerradas; Compañías Abiertas; Agresividad Fiscal

\section{Introdução}

A presente pesquisa tem como objetivo verificar a alíquota de impostos em empresas de capital abertas e fechadas no Brasil no período de 2010, após a adoção do IFRS, até 2015. A análise envolve a taxa efetiva do imposto (ETR) buscando identificar se há diferenças entre o grupo composto por empresas de sociedades de capital fechado e de capital aberto listadas na BM\&F Bovespa e a agressividade tributária.

Este assunto é relevante, pois o Brasil possui alta carga tributária e complexidade no sistema tributário vigente, tema este que tem assumido grande relevância no âmbito político e econômico, contribuindo para a literatura concernente à comparação entre companhias abertas e fechadas, visto serem muito escassas as pesquisas científicas em se tratando de companhias fechadas; assim, o estudo propicia um melhor entendimento da gestão de empresas de maiores portes que possuem grande representatividade na economia brasileira.

As empresas fechadas são predominantes em economias ao redor do mundo. A lista de 2016 Forbes das maiores empresas privadas no US4 inclui 223 empresas com receita superior a US \$ 2 bilhões. Nos mercados emergentes, a proeminência das empresas privadas é ainda mais exacerbada. De acordo com a $S$ \& $P$ Capital IQ, 5 empresas privadas possuem maior valor de mercado agregado do que as empresas públicas no Brasil. (COELHO; GALDI; LOPES, 2017).

O Brasil é ainda um dos países com um elevado índice de impostos incidentes sobre as operações realizadas pelas pessoas físicas e pessoas jurídicas (SANTOS et al. 2008). Conforme Tang (2005) considerase o gerenciamento tributário um meio para incentivar a diminuir os tributos, reduzindo a carga tributária elevada. A carga tributária no Brasil, de acordo com o estudo da Secretaria da Receita Federal do Brasil, atingiu 33,47\% do PIB de 2014.

Para medir a agressividade fiscal e investigar sua relação com a origem do capital, entre as métricas disponíveis na literatura, destacam-se nos estudos envolvendo agressividade fiscal a effective tax rate - ETR como mostra estudo feito por Hanlon e Heitzman (2010) em revisão de pesquisas tributárias que conclui a ETR como medida importante de captura de agressividade fiscal.

De acordo com a explicação de Fernández-Rodríguez e Martínez-Arias (2014), não há consenso sobre as principais variáveis que explicam a ETR (tamanho, intensidade de capital e inventário, alavancagem e rentabilidade da empresa), posto que os resultados encontrados até este momento não são conclusivos. Evidenciam-se entre os países diferenças significativas, dentro até mesmo de seu contexto econômico interno.

Apesar de no mercado brasileiro a maioria das empresas serem constituídas na forma de sociedades limitadas ou sociedades anônimas fechadas, poucos estudos levam em consideração esse tipo de empresa. O trabalho de França e Monte (2018) aborda diretamente o tema de ETR em companhias abertas e fechadas no Brasil e investiga a relação entre ETR das empresas abertas e fechadas controlando, entre outros,pelo ciclo de vida organizacional. Os autores encontraram que empresas brasileiras de capital fechado apresentam ETRs menores em relação às empresas abertas e, que os estágios de maturidade e turbulência do ciclo de vida organizacional têm relação com ETR.

Há diversos estudos que abordam os determinantes da Taxa Efetiva do Imposto de Renda (ETR) no âmbito das empresas listadas em Bolsa de Valores, que representam a minoria no Brasil. No entanto, conforme Coelho e Lima (2009), o grupo de companhias de capital fechado é, por outro lado, pouco estudado quanto a suas práticas contábeis, pela dificuldade de acesso aos dados dessas empresas. Assim, este estudo se propõe evidenciar a questão: as empresas de capital fechado são mais agressivas tributariamente do que as empresas de capital aberto? Neste estudo foi adotada a seguinte hipótese metodológica: Empresas de capital fechado são mais agressivas tributariamente do que as empresas de capital aberto, portanto deveriam possuir menor ETR. Esta conjectura é colocada pois dado que há menos monitoramento sobre os números de empresas fechadas. Os números de empresas listadas sofrem escrutínio de analistas de mercado, das grandes empresas de auditoria independentes e de diversos acionistas interessados nos resultados da empresa, enquanto as sociedades fechadas têm um conjunto de stakeholders mais restrito. Conforme Ball e Shivakumar (2005); Chen et al (2010); Kosi e Valenticic (2013); Lin, Mills e Zhang (2014), as empresas são mais propensas a serem influenciadas pela tributação e, portanto, as empresas fechadas são mais (provavelmente) agressivas.

Contudo, nossos resultados indicam que as empresas fechadas possuem ETR maior do que as abertas quando se controla por auditoria, intensidade de capital, estoque, alavancagem, rentabilidade e tamanho. Nosso resultado difere do resultado de França e Monte (2018) para mercado brasileiro. Este resultado é de interesse para autoridades fiscais e gestores tributários, pois evidencia que as companhias abertas possuem uma gestão tributária que resulta em menores taxas efetivas de pagamento de impostos. 


\section{Referencial Teórico}

\subsection{Gerenciamento Tributário}

O gerenciamento de resultados tributários decorre da exigência das empresas em diminuir o efeito econômico dos impostos nas contas de resultados, especialmente no que tange ao lucro das empresas. $O$ gerenciamento tributário pode influenciar no montante atribuído à distribuição de dividendos e nos rendimentos reportados aos stakeholders e shareholders (PAULO; MARTINS; CORRAR, 2007).

Martinez $(2008$, p. 8) evidencia que um dos produtos mais importantes da contabilidade para os usuários externos é o resultado (lucro/prejuízo) e que parte desse resultado pode decorrer de ajustes contábeis de natureza discricionária, não tendo qualquer relação com a realidade do negócio da empresa. $O$ autor acrescenta que os executivos são, em geral, motivados por influências exógenas e internas à empresa, conduzindo-os a gerenciar o resultado contábil na direção em que se deseja.

Portanto, uma das possibilidades de investigar de forma empírica o comportamento de gerenciamento tributário é a avaliação da alíquota efetiva de imposto ou effective tax rate (ETR). A ETR vem sendo utilizada pela literatura como proxy para medir o gerenciamento tributário (MILLS; NEWBERRY; TRAUTMAN, 2002; SHACKELFORD; SHEVLIN, 2001; MINNICK; NOGA, 2010; HUSEYNOV; KLAM, 2012).

\subsection{Taxa de Imposto Efetiva (ETR) e Agressividade Fiscal}

De acordo com Shackelford e Shevlin (2001), a ETR é como um indicador que ampara os tomadores de decisão a detectarem o valor real desembolsado pelas organizações no que alcança ao volume de tributos recolhidos sobre o lucro, autorizando confrontar a carga real efetiva exercitada pela empresa com a carga determinada pela legislação tributária.

A Taxa de Imposto Efetiva é um parâmetro apropriado para sugerir o planejamento tributário. Desta forma, quando se obtém taxas efetivas de impostos baixas, isso é consequência do planejamento tributário que pode haver (SHACKELFORD; SHEVLIN, 2001).

Hanlon e Heitzman (2010) listaram doze variáveis diferentes, sendo que a ETR e suas variações tiveram destaque. A ETR calculada pela divisão entre a despesa com tributos sobre o lucro e o resultado antes do imposto apresentada na Demonstração do Resultado do Exercício pode prover informações sobre o gerenciamento de resultados, porém não retrata estratégias de diferimento de tributos.

Lammersen (2002) acrescenta que a ETR é uma ferramenta gerencial extremamente útil para os economistas, políticos, contadores e administradores que precisam da informação condensada, porém sofisticada sobre a carga tributária.

Enquanto existe um amplo consenso sobre o seu efeito sobre a taxa de imposto efetiva (ETR) nas empresas brasileiras, existem resultados mistos em relação ao sinal da relação. Portanto, contribui com a nova evidência para o caso específico das companhias abertas e fechadas, realizando-se, assim, uma comparação.

Chen et al. (2010) descrevem por meio de medidas de planejamento tributário que a agressividade tributária é uma forma de diminuir gerencialmente o resultado tributário. Essas práticas podem incluir tanto medidas lícitas quanto medidas consideradas ilegais (ou abusivas).

Dunbar et al. (2010) fazem uma verificação das medidas de mensuração de agressividade fiscal exploradas na literatura. Os autores apontam que, das medidas de agressividade fiscal utilizadas geralmente, quatro são variantes da taxa de imposto efetiva (effective tax rate - ETR); duas são fundamentadas apenas em book-tax diferences (BTD); e outras três são fundamentadas em estimativas de modelos econométricos que capturam o comportamento anormal do planejamento tributário que pode ser reflexo de agressividade fiscal.

De acordo com Martinez e Dalfior (2015), a ETR possui um percentual de no máximo 34\%; as análises com resultados superiores a esse patamar são tratadas como menos agressivas tributariamente, enquanto as menores são tratadas como mais agressivas.

Hanlon e Heitzman (2010) mensuram a relação entre o Imposto de Renda e o Lucro antes do Imposto de Renda (LAIR), o qual é a métrica adotada que indica o grau do planejamento tributário agressivo das empresas.

\subsection{Hipótese}

De acordo com Coelho, Galdi e Lopes (2017), no Brasil a maioria das empresas comerciais e industriais são incorporadas sob duas formas: (i) Sociedades Limitadas (CL) e (ii) Sociedades por Ações (SA), ambas caracterizadas como empresas reponsabilidade limitada. As Sociedades Limitadas são sempre registradas como empresas de capital fechado, enquanto as Sociedades por Ações podem assumir a forma de empresa de capital aberto ou capital fechado (dependendo ou não se oferecem valores mobiliários ao mercado). As Sociedades Limitadas não são obrigadas a publicar demonstrações financeiras ou qualquer outra forma de informação financeira pública, independentemente de seu tamanho. O outro grupo Sociedades 
por Ações (SA) podem ser subdivididos em Companhias Abertas (SACA) - o grupo de empresas públicas e Companhias Fechadas (SACF) - o grupo de empresas privadas. No entanto, apenas a SACA tem ações listadas em Bolsa de Valores de São Paulo (BOVESPA).

Os resultados também contribuem para a literatura de gestão de resultados, sugerindo evidências anteriores em Beatty e Harris (1999) e Beatty, Bin e Petroni (2002), mostrando maior evidência de gerenciamento de lucros entre empresas abertas do que empresas fechadas, para bancos dos EUA, não sendo generalizável para um conjunto mais amplo de setores e países.

O meu trabalho buscou identificar diferenças entre a taxa de imposto efetiva no Brasil entre o grupo de empresas de Sociedades de capital fechado e as Sociedades de capital aberto listadas na BM\&F Bovespa e a agressividade fiscal.

Conforme Zimmerman (1983), considerando-se o aumento da alíquota tributária efetiva, que pode ser definida como o percentual de impostos pagos, no qual decorre a assimetria de tratamentos para fins contábeis e fiscais, suspeita-se que os grandes contribuintes que estão sujeitos aos custos políticos devem apresentar alíquota tributária efetiva superior aos demais contribuintes, pois não precisam adotar os procedimentos, por não estarem expostos aos custos políticos.

A pesquisa de Lennox, Lisowsky e Pittman (2013) estima a relação entre o planejamento tributário agressivo e a freqüência de supostas fraudes contábeis. Depois de confiar em um conjunto abrangente de taxa de imposto efetiva e proxies de diferença contábil-fiscal, bem como um fator comum extraído dessas medidas - para triangular suas evidências, geralmente encontra-se que as empresas públicas agressivas de impostos são menos propensas a manipular fraudulentamente seus recursos financeiros.

Os estudos de Lopes (2012) relatam que as grandes companhias de capital aberto pagam mais tributos do que as pequenas companhias de capital fechado. Os resultados indicam que as empresas fechadas terão o ETR menor, por serem mais agressivas tributariamente, dado que há menos monitoramento sobre os seus números divulgados e um custo político menor.

Kosi e Valentincic (2013) argumentam que muitas vezes as considerações fiscais geram contabilidade em empresas de capital fechado e acreditam que a qualidade contábil das empresas de capital fechado é afetada negativamente pela conformidade fiscal.

Pesquisa feita por Clatworthy e Peel (2013) relata que as empresas privadas são muitas vezes sujeitas a intervenções de políticas contábeis, embora existam relativamente poucas evidências em seus relatórios financeiros e práticas de governança.

De acordo com Cloyd, Pratt e Stock (1996), tais custos não tributários estão relacionados à estrutura de propriedade. Os autores argumentaram que, em relação às empresas de capital fechado, as empresas de capital aberto incorrem em custos não tributários superiores quando reduzem o lucro líquido reportado e, portanto, para um dado nível de poupança de impostos esperados, as empresas de capital aberto estão menos voltadas à contabilidade financeira e com métodos menos agressivos.

A partir do problema de pesquisa, foi formulada uma hipótese, tendo como base que a relação das empresas de capital fechado é mais agressiva tributariamente:

\section{capital aberto $(\beta \mathbf{i} \neq 0)$.}

\section{Metodologia}

A pesquisa identifica a Taxa do Imposto Efetiva nas empresas brasileiras, fazendo a comparação entre as companhias abertas e fechadas através de um estudo descritivo (VERGARA, 2011). Segundo Gitman (1997, p. 7), a sociedade anônima "tem poderes semelhantes aos de uma pessoa, no sentido de que pode acionar e ser acionada judicialmente, estabelecer contratos e ser parte deles, e adquirir propriedades em seu próprio nome". As sociedades anônimas são divididas em sociedades de capital aberto e de capital fechado.

Conforme Casagrande Neto (1985, p. 22) "é considerada companhia aberta toda sociedade anônima que tenha registro na Comissão de Valores Mobiliários (CVM) com consequente autorização para negociação de seus valores mobiliários em Bolsa ou balcão". Ainda para Casagrande Neto (1985, p. 22) a Sociedade Anônima Fechada é "aquela que adquire subscrição de ações por meio de recursos de capital pelos próprios acionistas ou por um grupo de pessoas restrito", não possuindo negociação de valores em bolsa ou balcão.

No Brasil, as companhias fechadas são de grande importância para a economia local. Constata-se que o somatório das receitas brutas das companhias fechadas demonstra, em média, $40 \%$ da receita bruta total das 500 maiores empresas nesse período (PAULO; ANTUNES; FORMIGONI, 2008).

A partir dos dados coletados das maiores companhias abertas e fechadas operantes no mercado brasileiro, estima-se o modelo de regressão da taxa do imposto efetiva como uma variável dependente contínua.

De acordo com pesquisadores como Armstrong et al. (2011), Callihan (1994), Comprix, Mills e Schmidt, (2011), Formigoni et al. (2009), Mills e Newberry (2001), Minnick e Noga, (2010) Shackelford e Shevlin (2000) Tang (2005), a ETR anual é definida como o percentual obtido pela divisão da despesa total com tributos sobre o lucro pelo lucro antes do Imposto de Renda de uma determinada empresa i no ano t: 


$$
\text { ETR } i, t=\frac{\text { Despesa } c / \text { IR CS i,t }}{\text { LAIR i, t }}
$$

Conforme Castro e Flach (2013), a despesa tributária é a soma das despesas com Imposto de Renda Corrente e contribuição social do ano corrente e o LAIR é o lucro da empresa antes do Imposto de Renda. Gomes (2016) considera que as empresas que praticam o gerenciamento tributário são aquelas que possuem índices de ETR inferiores que as alíquotas nominais dos tributos sobre o lucro, que no Brasil chega a 34\%.

Os dados da pesquisa selecionados foram das 500 maiores empresas de 2010 a 2015 de capital aberto e 498 maiores empresas também de 2010 a 2015 de capital fechado, disponíveis na base de dados da QUANTUM para identificação.

A QUANTUM é uma base de dados de uma empresa de tecnologia em finanças que atua no mercado desde 1999. Possui uma ampla base de informações financeiras (mais de 150.000 séries) atualizadas constantemente com dados quantitativos e qualitativos; ela possui uma base nova que fornece os dados das empresas fechadas. A QUANTUM possui uma plataforma desenvolvida exclusivamente para universidades, que possibilita a pesquisadores, professores e alunos acessarem as informações financeiras do mundo real (QUANTUM, 2016).

Foram excluídas as que dispunham de valores faltantes, tamanho $<1.000, \mathrm{ROA}=0, \mathrm{ETR}=0$, as empresas financeiras, setor de securitização de recebíveis, intermediação financeira e bancos em razão da legislação tributária possuir tratamento diferenciado destas empresas em relação às demais, o que pode acarretar impactos diferentes, restando 47 setores de acordo com a CVM.

A amostra foi winsorizada a $1 \%$, foram coletadas 5.988 observações. A amostra contém 3.597 observações, contendo apenas ETR>0, e foram excluídas 2.391 observações.

Então, de acordo com as variáveis observadas no Quadro 1, formulou-se um modelo para análise de dados em painel com efeito fixo, robusto e controlado por tempo(ano) e setor, com base nos estudos que analisaram as determinantes da ETR, como o estudo do Fernández-Rodríguez e Martínez-Arias (2014), Lazãr (2014) e Richardson e Lanis (2007), apresentando a classificação setorial das empresas estudadas, obtendo uma amostra bastante heterogênea, na medida em que apresenta empresas de diferentes setores e segmentos diferenciados. Desta forma, estabeleceu-se o seguinte modelo de regressão:

ETR $_{\mathrm{i}, \mathrm{t}}=\beta_{0}+\beta_{1}$ DFechada $_{\mathrm{i}, \mathrm{t}}+\beta_{2}$ DBigFour $+\beta_{3}$ Tam $+\beta_{4}$ Intcap $+\beta_{5}$ Est $+\beta_{67}$ Alav $+\beta_{7}$ Roa $+\varepsilon_{\mathrm{it}}$

A fórmula apresenta como variável dependente a taxa de imposto efetiva (ETR), e como variáveis independentes, o tamanho da empresa (TAM), a intensidade de capital (INTCAP), o estoque (EST), a alavancagem da empresa (ALAV), a rentabilidade (ROA), Big-Four e Fechada.

A partir da revisão da literatura realizada, determinaram-se as variáveis selecionadas para esta investigação, as quais são apresentadas no Quadro 1.

\begin{tabular}{|c|c|c|}
\hline Tipo & Variáveis & Descrição \\
\hline Dependente & ETR & $\begin{array}{c}\text { Taxa de Imposto Efetiva (Despesa p/ IR Corrente e CS/ Lucro antes da } \\
\text { despesa do IR e CS) }\end{array}$ \\
\hline \multirow{7}{*}{ Independentes } & FECHADA & Variável Dummy que é igual a 1 se a empresa é fechada ou 0 caso contrário. \\
\hline & BIG-FOUR & $\begin{array}{c}\text { Variável Dummy que é igual a } 1 \text { se possui auditoria Big-four ou } 0 \text { caso não seja } \\
\text { Big-four. }\end{array}$ \\
\hline & TAM & Tamanho (Log do Ativo Total) \\
\hline & INTCAP & Intensidade de Capital (Ativos fixos tangíveis / Ativo Total) \\
\hline & EST & (Estoques / Ativo total) \\
\hline & ALAV & Alavancagem (Dívidas de L.P. / Patrimônio Líquido) \\
\hline & ROA & Rentabilidade (Lucro líquido / Ativo Total) \\
\hline
\end{tabular}

Fonte: Dados da pesquisa

\section{Análise e Discussão dos Resultados}

\subsection{Estatística Descritiva}

Nesta seção, apresentam-se a análise e a apresentação de resultados da pesquisa. Inicialmente, os resultados da estatística descritiva; a amostra foi do período considerado (2010-2015), sendo coletadas 3.597 observações (firmas-ano) no total de 998 empresas, sendo 500 empresas de capital aberto e 498 de capital fechado. 
Tabela 1: Estatística Descritiva das Empresas Abertas e Fechadas

\begin{tabular}{ccccccccccccc}
\hline Variaveis & Média A & Média F & DP A & DP F & Mín. A & Mín. F & p 50 A & p50 F & Máx. A & Máx.B & N A & N F \\
ETR & 0.267 & 0.288 & 0.152 & 0.154 & 0.000 & 2.130 & 0.274 & 0.297 & 0.880 & 0.880 & 1690 & 1978 \\
Big-Four & 0.776 & 0.395 & 0.417 & 0.489 & 0.000 & 0.000 & 1.000 & 0.000 & 1.000 & 1.000 & 1690 & 1978 \\
Intensidade de Capital & 0.253 & 0.266 & 0.253 & 0.228 & 0.000 & 0.000 & 0.168 & 0.223 & 0.935 & 0.935 & 1690 & 1978 \\
Estoque & 0.067 & 0.106 & 0.091 & 0.117 & 0.000 & 0.000 & 0.009 & 0.066 & 0.461 & 0.461 & 1690 & 1978 \\
Alavancagem & 0.225 & 0.126 & 0.166 & 0.145 & 0.000 & 0.000 & 0.217 & 0.083 & 0.704 & 0.704 & 1690 & 1978 \\
Rentabilidade & 0.045 & 0.064 & 0.085 & 0.094 & -0.537 & -0.537 & 0.044 & 0.057 & 0.400 & 0.400 & 1690 & 1978 \\
Tamanho & 14.470 & 13.734 & 1.746 & 1.281 & 9.449 & 9.449 & 14.578 & 13.610 & 18.317 & 17.845 & 1690 & 1978
\end{tabular}

A = Empresas Abertas

$\mathrm{F}=$ Empresas Fechadas

Fonte: Quantum Axis $\AA^{\circledR}$ e Economática ${ }^{\circledR}$

Conforme Tabela 1, as empresas abertas representam $46 \%$ da amostra, sendo 1.690 observações. Pode-se observar que a média da ETR é 0,267 e com um mínimo de 0,000 e máximo de 0,880. Na mesma tabela as empresas de capital fechado representam $54 \%$ da amostra, sendo 1.978 observações. Pode-se observar que a média da ETR é de 0,228 e com mínimo de 2.130 e o máximo 0,880.

A tabela 1 também aponta para uma média superior no tamanho das companhias abertas em relação às fechadas e para uma intensidade de capital de 0,25 nas empresas abertas e de 0,27 nas empresas fechadas. Com relação ao nível de estoque as abertas possuem média de 0,07 enquanto as fechadas de 0,11 . A rentabilidade medida pelo ROA das companhias abertas é em média $4,5 \%$ enquanto a das fechadas é de $6,4 \%$. Finalmente, conforme esperado, a alavancagem média das empresas abertas é bem superior do que a alavancagem das empresas fechadas. Na Tabela 2, mostra-se a matriz de correlação de Spearman das empresas abertas e fechadas.

Tabela 2: Matriz de Correlação de Spearman das Empresas Abertas e Fechadas

\begin{tabular}{|c|c|c|c|c|c|c|c|c|}
\hline & ETR & Fechado & Big-four & $\begin{array}{l}\text { Intensidade } \\
\text { de Capital }\end{array}$ & Estoque & $\begin{array}{c}\text { Alavancage } \\
\text { m }\end{array}$ & $\begin{array}{c}\text { Rentabilidad } \\
\text { e }\end{array}$ & Tamanho \\
\hline ETR & 1.0000 & & & & & & & \\
\hline Fechado & $0.0803 *$ & 1.0000 & & & & & & \\
\hline Big-Four & $-0.0359 *$ & $-0.3831^{*}$ & 1.0000 & & & & & \\
\hline Intensidade de Capital & -0.0058 & $0.0884 *$ & $-0.0576^{*}$ & 1.0000 & & & & \\
\hline Es toque & $-0.0969 *$ & $0.1479 *$ & $-0.1572 *$ & $0.1849 *$ & 1.0000 & & & \\
\hline Alavancagem & 0.0220 & $-0.3220 *$ & $0.2872 *$ & $0.1622 *$ & $-0.1049 *$ & 1.0000 & & \\
\hline Rentabilidade & $-0.1146^{*}$ & $0.1084^{*}$ & $-0.0328 *$ & $-0.2028 *$ & $-0.0918^{*}$ & $-0.2476^{*}$ & 1.0000 & \\
\hline Tamanho & -0.0193 & $-0.2619 *$ & $0.4067 *$ & 0.0243 & $-0.1259 *$ & $0.3898 *$ & $-0.1417 *$ & 1.0000 \\
\hline
\end{tabular}

Fonte: Dados da pesquisa

A tabela 2 mostra uma correlação de $8 \%$ da variável ETR com empresas fechadas denotando uma associação positiva entre as variáveis. As variáveis Big-Four, Estoque e Rentabilidade apresentaram uma associação negativa com o ETR. A tabela 3 apresenta o resultado dos testes de média da variável ETR para as empresas abertas e fechadas denotando, a 5\%, que o ETR das empresas fechadas é superior ao das empresas abertas.

Tabela 3: Teste de Média da ETR das Empresas Abertas e Fechadas

\begin{tabular}{c|cccccc}
\hline Grupo & Número & Média & Erro Padrão & Des vio Padrão & Intervalo de Confiança 95\% \\
\hline Abertas & 1619 & 0.267 & 0.004 & 0.152 & 0.260 & 0.275 \\
Fechadas & 1978 & 0.288 & 0.003 & 0.154 & 0.281 & 0.294 \\
\hline Combinado & 3597 & 0.278 & 0.003 & 0.153 & 0.273 & 0.283 \\
\hline Diferença & \multicolumn{7}{|c}{-0.020} & 0.005 & & -0.030 & -0.010 \\
\hline Diferença = média abertas - média fechadas & & & $\mathrm{t}=$ & -3.982
\end{tabular}

Diferença $=$ média abertas - média fechadas

$\mathrm{t}=$

$\mathrm{Ho}=$ Diferença $=0$

Fonte: Dados da pesquisa

A Tabela 4 mostra a estatística descritiva da amostra, dividida por setores de classificação da Comissão de Valores Mobiliários (CVM), no qual são 47 setores ao total inseridos na amostra. Pode-se observar que o setor Energia Elétrica possui a maior frequência, de 404, tendo 11,23\% da amostra. Logo a

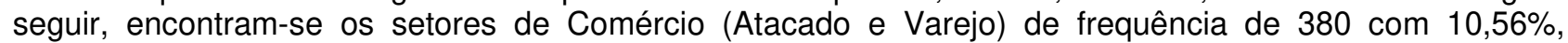
Construção Civil, Mat.Const. e Decoração, de frequência de 341 com 9,48\%. Em contrapartida, o setor de Emp.Adm.Part - Hospedagem e Turismo possui a menor frequência de 3 e 0,06\% da amostra. 
Tabela 4: Setores da Comissão de Valores Mobiliários

\begin{tabular}{|c|c|c|c|}
\hline Setor CVM & Frequência & Percentual & $\begin{array}{l}\text { Percentual } \\
\text { Acumulada }\end{array}$ \\
\hline Agricultura (Açúcar, Álcool e Cana) & 70 & 1.95 & 1.95 \\
\hline Alimentos & 200 & 5.56 & 7.51 \\
\hline Bebidas e Fumo & 17 & 0.47 & 7.98 \\
\hline Brinquedos e Lazer & 10 & 0.28 & 8.26 \\
\hline Comunicação e Informática & 68 & 1.89 & 10.15 \\
\hline Comércio (Atacado e Varejo) & 380 & 10.56 & 20.71 \\
\hline Construção Civil, Mat. Constr. e Decoração & 341 & 9.48 & 30.19 \\
\hline Educação & 25 & 0.70 & 30.89 \\
\hline Embalagens & 28 & 0.78 & 31.67 \\
\hline Emp. Adm. Part. - Alimentos & 5 & 0.14 & 31.80 \\
\hline Emp. Adm. Part. - Brinquedos e Lazer & 6 & 0.17 & 31.97 \\
\hline Emp. Adm. Part. - Comunicação e Informática & 6 & 0.17 & 32.14 \\
\hline Emp. Adm. Part. - Comércio (Atacado e Varejo) & 22 & 0.61 & 32.75 \\
\hline Emp. Adm. Part. - Const. Civil, Mat. & 10 & 0.28 & 33.03 \\
\hline Emp. Adm. Part. - Educação & 5 & 0.14 & 33.17 \\
\hline Emp. Adm. Part. - Embalagens & 3 & 0.08 & 33.25 \\
\hline Emp. Adm. Part. - Energia Elétrica & 56 & 1.56 & 34.81 \\
\hline Emp. Adm. Part. - Extração Mineral & 7 & 0.19 & 35.00 \\
\hline Emp. Adm. Part. - Farmacêutico e Higiene & 4 & 0.11 & 35.11 \\
\hline Emp. Adm. Part. - Hospedagem e Turismo & 2 & 0.06 & 35.17 \\
\hline Emp. Adm. Part. - Metalurgia e Siderurgia & 15 & 0.42 & 35.59 \\
\hline Emp. Adm. Part. - Máqs., Equip., Veíc. & 15 & 0.42 & 36.00 \\
\hline Emp. Adm. Part. - Papel e Celulose & 5 & 0.14 & 36.14 \\
\hline Emp. Adm. Part. - Petroquímicos e Borracha & 6 & 0.17 & 36.31 \\
\hline Emp. Adm. Part. - Petróleo e Gás & 6 & 0.17 & 36.47 \\
\hline Emp. Adm. Part. - Saneamento, Serv. Água & 6 & 0.17 & 36.64 \\
\hline Emp. Adm. Part. - Sem Setor Principal & 300 & 8.34 & 44.98 \\
\hline Emp. Adm. Part. - Serviços Transporte & 30 & 0.83 & 45.81 \\
\hline Emp. Adm. Part. - Telecomunicações & 17 & 0.47 & 46.28 \\
\hline Emp. Adm. Part. - Têxtil e Vestuário & 6 & 0.17 & 46.45 \\
\hline Energia Elétrica & 404 & 11.23 & 57.68 \\
\hline Extração Mineral & 44 & 1.22 & 58.90 \\
\hline Farmacêutico e Higiene & 74 & 2.06 & 60.96 \\
\hline Gráficas e Editoras & 54 & 1.50 & 62.46 \\
\hline Hospedagem e Turismo & 10 & 0.28 & 62.74 \\
\hline Metalurgia e Siderurgia & 162 & 4.50 & 67.24 \\
\hline Máquinas, Equipamentos, Veículos e Peças & 215 & 5.98 & 73.22 \\
\hline Não classificado & 51 & 1.42 & 74.64 \\
\hline Papel e Celulose & 47 & 1.31 & 75.95 \\
\hline Petroquímicos e Borracha & 66 & 1.83 & 77.78 \\
\hline Petróleo e Gás & 69 & 1.92 & 79.70 \\
\hline Saneamento, Serv. Água e Gás & 95 & 2.64 & 82.34 \\
\hline Seguradoras e Corretoras & 43 & 1.20 & 83.54 \\
\hline Serviços Transporte e Logística & 336 & 9.34 & 92.88 \\
\hline Serviços médicos & 50 & 1.39 & 94.27 \\
\hline Telecomunicações & 77 & 2.14 & 96.41 \\
\hline Têxtil e Vestuário & 129 & 3.59 & 100.00 \\
\hline Total & 3597 & 100.00 & \\
\hline
\end{tabular}

Fonte: Dados da pesquisa

\subsection{Resultados das Regressões}

A Tabela 5 apresenta os principais resultados da pesquisa. A regressão realizada para a avaliação da relação entre a estrutura societária da empresa (aberta ou fechada) e sua taxa efetiva de imposto (ETR) foi realizada levando-se em consideração efeito fixo de ano e de setor. A amostra analisada na regressão é composta de 3.597 observações, excluindo-se e somente considera empresas com ETR $>0$.

De maneira geral os resultados da Tabela 5 apontam para uma relação positiva e significante entre empresas fechadas e ETR. O coeficiente encontrado foi de 0,023 indicando que em média, mesmo após controlar pelo auditor, pela intensidade de capital, pelo nível de estoque, alavancagem, rentabilidade e tamanho, as empresas fechadas apresentam ETR 2,3\% superior ao das companhias abertas. Este resultado denota uma maior eficiência na gestão tributária das companhias abertas em relação às fechadas. $O R^{2}$ ajustado encontrado é 0,064 , ou seja, $6,4 \%$ das variações do ETR são explicados pela regressão apresentadas. A estatística $\mathrm{F}$ é significativa e indica uma razoabilidade do modelo proposto. 
Tabela 5: Regressão Linear com ETR>0

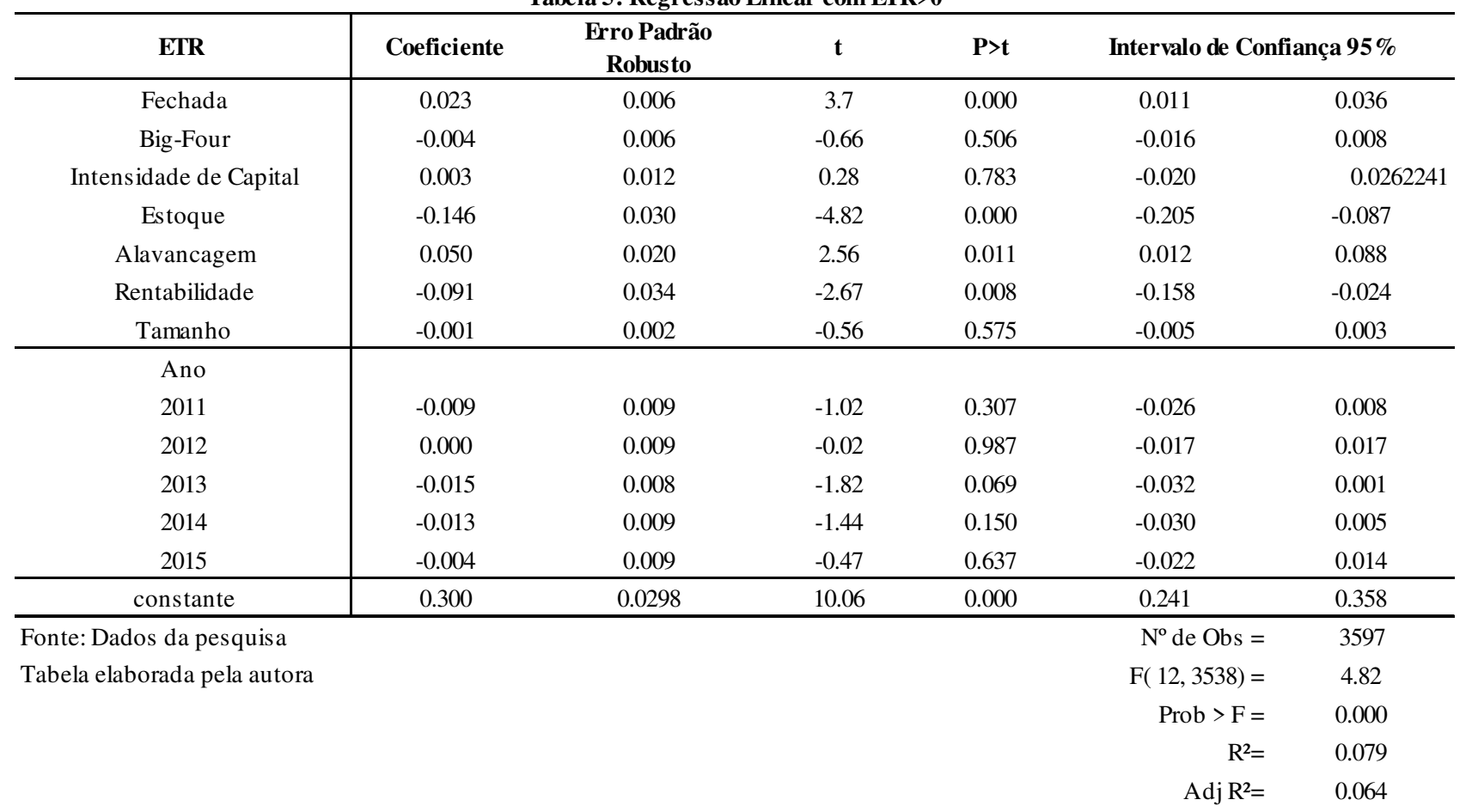

Os coeficientes das variáveis Intensidade de Capital e Tamanho não foram significativos denotando que não há relação entre elas e a Taxa de Imposto Efetiva (ETR) das empresas. Também não foi significativo o coeficiente relacionado a variável big four, denotando que a escolha do auditor não tem relação direta com a variável ETR.

As demais variáveis de controle no modelo se demonstraram significativas, sendo que há relação positiva entre alavancagem e ETR e uma associação negativa entre estoque, rentabilidade e tamanho com a variável dependente. Assim, empresas com maior níveis de estoque, maior rentabilidade e com maiores ativos possuem, em média, menor ETR.

\section{Conclusões}

O estudo teve como objetivo analisar se há diferenças entre agressividade fiscal medida pela taxa de imposto efetiva (ETR), fazendo uma comparação entre empresas de capital aberto e fechado entre 2010 e 2015, após a adoção do IFRS no mercado brasileiro.

As variáveis foram testadas em uma amostra contendo as maiores empresas de capital aberto e fechado atuantes no Brasil, da qual subtraíram-se as financeiras, companhias de securitização de recebíveis, intermediação financeira e bancos, em razão da legislação tributária diferenciada em relação às demais e também estarem sujeitas à regulamentação específica.. A amostra final foi composta de 1690 observações de companhias abertas e 1978 observações de empresas fechadas. Os dados da amostra foram winsorizados a $1 \%$ de maneira a se diminuir os impactos de observações extremas.

Os resultados evidenciam que que as empresas fechadas possuem ETR maior, mesmo quando se controla por auditoria, intensidade de capital, estoque, alavancagem, rentabilidade e tamanho.

A variável big-four não foi significante, ou seja, não influencia na média da ETR. Estudos anteriores de Wang, Campbell e Johnson (2014) evidenciam que a empresa ser auditada por uma das big-four não afeta a ETR, e acreditam que as big-four apresentam diferentes culturas nacionais de auditoria, que podem oferecer estratégias diferentes às empresas. Ainda em linha com os nossos resultados, o estudo de FernandezRodriguez (2004) mostra que não há relação direta entre a intensidade de capital e a ETR.

Os resultados evidenciaram também que quanto maior o nível estoque menor será a ETR. Estudos anteriores realizados por Fernández-Rodriguez (2004), Gupta e Newberry (1997) e Richardson e Lanis (2007) encontraram uma relação estaticamente significativa. Os estudos de Chen et al. (2011) e Harris e Feeny (2003) mostram que quanto maior a alavancagem, maior será o ETR.

A partir dos resultados encontrados, evidenciou-se que quanto maior a Rentabilidade, menor é a ETR, e quanto mais rentável é a empresa, menor é a ETR, ou seja, a empresa faz planejamento tributário. Analisouse que, de acordo com Lazăr (2014), a rentabilidade também influencia a ETR, usando o retorno sobre os ativos (ROA), o que também afirmam os estudos anteriores de Gupta e Newberry (1997), Janssen (2005) e Richardson e Lanis (2007). Nos estudos anteriores de Derashid e Zhang (2003) e Noor (2010), as empresas mais rentáveis têm uma carga fiscal menor, devido à compensação fiscal concedida pelo governo às empresas mais eficientes. 
As evidências em relação à variável tamanho não influencia na ETR, em consonância com o que afirma os trabalhos anteriores de Fernández-Rodríguez (2004), Gupta e Newberry (1997), Liu e Cao (2007), que não mostram qualquer influência significativa entre o tamanho da empresa e a ETR.

Conforme Pierk (2016), as empresas de capital aberto têm custos maiores, devido à maior quantidade de divulgação e custos associados a menor agressividade fiscal; portanto, maiores taxas de impostos efetivas. Assim, os participantes do mercado de capitais também poderiam incentivar os gerentes de empresas abertas a serem mais agressivos do que as empresas de capital fechado.

Já conforme Mills e Newberry (2001), do ponto de vista da política tributária, os resultados deste estudo sugerem que a dependência das diferenças de renda contábil-fiscal como indicador de posições tributárias agressivas pode ser menos útil para as empresas fechadas, porque elas têm menos incentivos para reportar rendimentos discordantes.

Este trabalho adiciona à literatura ao apresentar a comparação entre companhias abertas e fechadas, apresentando um melhor entendimento da gestão tributária destes diferentes tipos societários de empresas, especialmente ao se considerar sua representatividade na economia brasileira.

É relevante mencionar possibilidades de futuras pesquisas e aprofundamentos pertinentes ao tema desenvolvido, principalmente em se tratando de pesquisas científicas relacionadas a companhias fechadas, pela dificuldade ao acesso ao banco de dados, tendo em vista que pesquisas em contabilidade em empresas fechadas são praticamente inexistentes.

\section{Referências}

ARMSTRONG, Christopher S.; BLOUIN, Jennifer L.; LARCKER, David F. The incentives for tax planning. Rock Center for Corporate Governance at Stanford University Working Paper, n. 56. Disponível em: $<$ https://www.journals.elsevier.com/journal-of-accounting-and-economics/>. Acesso em: 05 out. 2016.

BALL, Ray; SHIVAKUMAR, Lakshmanan. Earnings quality in UK private firms: comparative loss recognition timeliness. Journal of Accounting and Economics, v. 39, n. 1, p. 83-128, 2005. DOI:

https://doi.org/10.1016/j.jacceco.2004.04.001

BEATTY, Anne L.; BIN, K.; PETRONI, Kathy R. Earnings management to avoid earnings declines across publicly and privately held banks. The Accounting Review, v. 77, n. 3, p. 547-570, 2002. Disponível em: https://www.jstor.org/stable/3068887. Acesso em: 11 dez. 2016.

BEATTY, Anne; HARRIS, David G. The effects of taxes, agency costs and information asymmetry on earnings management: A comparison of public and private firms. Review of Accounting Studies, v. 4, n. 34, p. 299-326, 1999. DOI: https://doi.org/10.1023/A:1009642403312.

CALLIHAN, Debra S. Corporate effective tax rates: A synthesis of the literature. Journal of Accounting Literature, v. 13, p. 1, 1994.

CASAGRANDE NETO, Humberto; SOUZA, Lucy A.; ROSSI, Maria Cecília. Abertura do capital de empresas no Brasil: um enfoque prático. São Paulo: Atlas, 2000.

CASTRO, Jessica Kopak; FLACH, Leonardo. O gerenciamento tributário relacionado ao desempenho das empresas: um estudo nas empresas listadas no nível 1 de governança corporativa da BM\&FBOVESPA. In: Seminário de Administração-SEMEAD, 13., São Paulo, Anais... São Paulo.

CHEN, Feng, HOPE, Ole-Kristian, LI, Qingyuan; WANG, Xin. Financial reporting quality and investment efficiency of private firms in emerging markets. Accounting Review, v. 86, n. 4, p. 1255-1288, 2011. Disponível em: https://www.jstor.org/stable/23045602. Acesso em: 10 dez. 2016

CHEN, Shuping; CHEN, Xia; CHENG, Qiang; SHEVLIN, Terry. Are family firms more tax aggressive than non-family firms?. Journal of Financial Economics, v. 95, n. 1, p. 41-61, 2010. DOI:

https://doi.org/10.1016/j.jfineco.2009.02.003

CLATWORTHY, Mark A.; PEEL, Michael J. The impact of voluntary audit and governance characteristics on accounting errors in private companies. Journal of Accounting and Public Policy, v. 32, n. 3, p. 1-25, 2013. DOI: https://doi.org/10.1016/j.jaccpubpol.2013.02.005.

CLOYD, C. Bryan; PRATT, Jamie; STOCK, Toby. The use of financial accounting choice to support aggressive tax positions: Public and private firms. Journal of Accounting Research, p. 23-43, 1996. DOI: $10.2307 / 2491330$. 
COELHO, Antonio Carlos; GALDI, Fernando Caio; LOPES, Alexsandro Broedel. Determinants of asymmetric loss recognition timeliness in public and private firms in Brazil. Emerging Markets Review, v. 31, p. 65-79, 2017. DOI: https://doi.org/10.1016/j.ememar.2017.02.002.

COELHO, Antonio Carlos; LIMA, Iran Siqueira. Gerenciamento de resultados contábeis no Brasil: comparação entre companhias de capital fechado e de capital aberto. Revista de Administração-RAUSP, v. 44, n. 3, p. 207-221, 2009. Disponível em: <http://www.redalyc.org/html/2234/223417462003/>. Acesso em: 25 jul. 2017.

COMPRIX, Joseph; MILLS, Lillian F.; SCHMIDT, Andrew P. Bias in quarterly estimates of annual effective tax rates and earnings management. Journal of the American Taxation Association, v. 34, n. 1, p. 31-53, 2011. DOI: https://doi.org/10.2308/atax-10152

FRANÇA R.D.; MONTE, P.A. As empresas brasileiras de capital fechado são mais agressivas em suas effective tax rate (etr) do que as de capital aberto?. Reunir: Revista de administração, contabilidade e sustentabilidade, v. 8, n. 1, 2018.

DERASHID, Chek; ZHANG, Hao. Effective tax rates and the "industrial policy" hypothesis: evidence from Malaysia. Journal of International Accounting, Auditing and Taxation, v. 12, n. 1, p. 45-62, 2003. DOI: https://doi.org/10.1016/S1061-9518(03)00003-X.

DUNBAR, Amy et al. What do measures of tax aggressiveness measure. In: Proceedings of the National Tax Association Annual Conference on Taxation. 2010. p. 18-26.

FERNÁNDEZ-RODRÍGUEZ, Elena; MARTÍNEZ-ARIAS, Antonio. Determinants of the effective tax rate in the BRIC countries. Emerging Markets Finance and Trade, v. 50, sup3, p. 214-228, 2014. DOI:

10.2753/REE1540-496X5003S313. Disponível em: <http://www.tandfonline.com/doi/abs/10.2753/REE1540496X5003S313>. Acesso em: 28 out 2016.

FINGER JUNIOR, José Ireneu; BALESTRIN, Rubiana; GALIOTTO, Simone. O novo código civil e a sociedade limitada na região do meio oeste catarinense. Revista Catarinense da Ciência Contábil, v. 4, n. 11, p. 37-50, 2005. DOI: http://dx.doi.org/10.16930/2237-7662/rccc.v4n11p37-50

FORMIGONI, Henrique; ANTUNES, Maria Thereza Pompa; PAULO, Edilson. Diferença entre o lucro contábil e lucro tributável: uma análise sobre o gerenciamento de resultados contábeis e gerenciamento tributário nas companhias abertas brasileiras. BBR-Brazilian Business Review, v. 6, n. 1, 2009. DOI: http://dx.doi.org/10.15728/bbr.2009.6.1.3

FRANÇA, Jose Antonio; CUNHA, George Henrique de Moura; CUNHA, Danial Pereira. Adoção do Padrão IRFS no Brasil: Impacto do Custo Atribuído no Grau de Endividamento (GE) e no Retorno Sobre o Ativo (RSA) das Empresas. Revista de Educação e Pesquisa em Contabilidade (REPeC), v. 8, n. 2, 180-194, 2014. DOI: https://doi.org/10.17524/repec.v8i2.1037.

GITMAN, Lawrence J. Princípios de administração financeira. São Paulo: Harbra, 1997.

GOMES, Antônio Paulo Machado. Características da governança corporativa como estímulo à gestão fiscal. Revista Contabilidade \& Finanças, v. 27, n. 71, p. 149-168, 2016.

DOI: https://doi.org/10.1590/1808-057x201500750

GUPTA, Sanjay; NEWBERRY, Kaye. Determinants of the variability in corporate effective tax rates:

Evidence from longitudinal data. Journal of Accounting and Public Policy, v. 16, n. 1, p. 1-34, 1997. DOI: https://doi.org/10.1016/S0278-4254(96)00055-5.

HANLON, Michelle; HEITZMAN, Shane. A review of tax research. Journal of Accounting and Economics, v. 50, n. 2-3, p. 127-178, 2010. DOI: https://doi.org/10.1016/j.jacceco.2010.09.002.

HARRIS, Mark N.; FEENY, Simon. Habit persistence in effective tax rates. Applied Economics, v. 35, n. 8, p. 951-958, 2003. DOI: https://doi.org/10.1080/0003684032000050577.

HUSEYNOV, Fariz; KLAMM, Bonnie K. Tax avoidance, tax management and corporate social responsibility. Journal of Corporate Finance, v. 18, n. 4, p. 804-827, 2012. DOI: https://doi.org/10.1016/j.jcorpfin.2012.06.005. 
JANSSEN, Boudewijn. Corporate effective tax rates in the Netherlands. De Economist, v. 153, n. 1, p. 4766, 2004. DOI: https://doi.org/10.1111/1475-679X.00095

KOSI, Urska; VALENTINCIC, Aljosa. Write-offs and profitability in private firms: Disentangling the impact of tax-minimisation incentives. European Accounting Review, v. 22, n. 1, p. 117-150, 2013. DOI: https://doi.org/10.1080/09638180.2012.661938.

LAMMERSEN, Lothar. The Measurement of Effective Tax Rates: Common Themes in Business Management and Economics. ZEW Discussion Papers, 02-46, 2002. Disponível em: <https://www.econstor.eu/bitstream/10419/24639/1/dp0246.pdf>. Acesso em: 11 nov. 2016.

LAZĂR, Sebastian. Determinants of the variability of corporate effective tax rates: Evidence from Romanian listed companies. Emerging Markets Finance and Trade, v. 50, sup4, p. 113-131, 2014. DOI: 10.2753/REE1540-496X5004S4007.

LENNOX, Clive; LISOWSKY, Petro; PITTMAN, Jeffrey. Tax aggressiveness and accounting fraud. Journal of Accounting Research, v. 51, n. 4, p. 739-778, 2013. DOI: 10.1111/joar.12002.

LIN, Kenny Z.; MILLS, Lillian F.; ZHANG, Fang. Public versus private firm responses to the tax rate reduction in China. The Journal of the American Taxation Association, v. 36, n. 1, p. 137-163, 2013. DOI: https://doi.org/10.2308/atax-50618.

LIU, Xing; CAO, Shujun. Determinants of corporate effective tax rates: evidence from listed companies in China. Chinese Economy, v. 40, n. 6, p. 49-67, 2007. DOI: 10.2753/CES1097-1475400603.

LOPES, Tatiana. Custos políticos tributários: o impacto do tamanho na alíquota tributária efetiva. 2012. Tese de Doutorado em Controladoria e Contabilidade: Contabilidade, Faculdade de Economia, Administração e Contabilidade, Universidade de São Paulo, São Paulo, São Paulo - SP, Brasil.

MARTINEZ, Antonio Lopo. Detectando earnings management no Brasil: estimando os accruals discricionários. Revista Contabilidade \& Finanças, v. 19, n. 46, p. 7-17, 2008. DOI: https://doi.org/10.1590/S1519-70772008000100002.

MARTINEZ, Antonio Lopo; DALFIOR, Marcelo Domingos. Agressividade Fiscal entre Companhias Controladoras e Controladas. Revista da Receita Federal: estudos tributários e aduaneiros, v. 2, n. 1, p. 344-362, 2015. Disponível em:

<http://www.revistadareceitafederal.receita.fazenda.gov.br/index.php/revistadareceitafederal/article/view/16> Acesso em: 22 nov. 2016

MILLS, Lillian F.; NEWBERRY, Kaye J. The influence of tax and nontax costs on book-tax reporting differences: Public and private firms. Journal of the American Taxation Association, v. 23, n. 1, p. 1-19, 2001.DOI: https://doi.org/10.2308/jata.2001.23.1.1

MILLS, Lillian; NEWBERRY, Kaye; TRAUTMAN, William. Trends in book-tax income and balance sheet differences. Tax Notes, v. 19, n. 8, p. 491-521, 2002. In: SSRN: https://ssrn.com/abstract=324268

MINNICK, Kristina; NOGA, Tracy. Do corporate governance characteristics influence tax management?. Journal of Corporate Finance, v. 16, n. 5, p. 703-718, 2010.

DOI:10.1016/j.jcorpfin.2010.08.005.

NOOR, Rohaya Md et al. Corporate tax planning: A study on corporate effective tax rates of Malaysian listed companies. International Journal of Trade, Economics and Finance, v. 1, n. 2, p. 189, 2010. DOI: https://doi.org/10.7763/IJTEF.2010.V1.34

PAULO, Edilson; ANTUNES, Maria Thereza Pompa; FORMIGONI, Henrique. Conservadorismo contábil nas companhias abertas e fechadas brasileiras. RAE-Revista de Administração de Empresas, v. 48, n. 3, p. 46-60, 2008. DOI: https://doi.org/10.1590/S0034-75902008000300005.

PAULO, Edílson; MARTINS, Eliseu; CORRAR, Luiz João. Detecção do gerenciamento de resultados pela análise do diferimento tributário. Revista de Administração de Empresas, v. 47, n. 1, p. 46-59, $2007 .$.

PEEK, Erik; CUIJPERS, Rick; BUIJINK, Willem. Creditors' and shareholders' reporting demands in public versus private firms: Evidence from Europe. Contemporary Accounting Research, v. 27, n. 1, p. 49-91, 
2010. DOI: https://doi.org/10.1111/j.1911-3846.2010.01001.x

PIERK, J.. Are private firms really more tax aggressive than public firms?. WU International Taxation Research Paper Series, v. 1, n. 2, 2016. DOI: http://dx.doi.org/10.2139/ssrn.2758756.

QUANTUM. Disponível em: http://www.quantumfinance.com.br/produtos/index.php. Acesso em: 17 ago. 2017.

RICHARDSON, Grant; LANIS, Roman. Determinants of the variability in corporate effective tax rates and tax reform: Evidence from Australia. Journal of Accounting and Public Policy, v. 26, n. 6, p. 689-704, 2007. DOI: https://doi.org/10.1016/j.jaccpubpol.2007.10.003. Disponível em:

<http://www.sciencedirect.com/science/article/pii/S0278425407000701>. Acesso em: 22 out. 2016.

SANTOS, Cláudio Hamilton Matos dos; RIBEIRO, Márcio Bruno; GOBETTI, Sérgio Wulff. A evolução da carga tributária bruta brasileira no período 1995-2007: tamanho, composição e especificações

econométricas agregadas. 2008. Working Paper, Texto para Discussão, No. 1350, Institute of Applied Economic Research (IPEA), Brasília. Disponível em:

<https://www.econstor.eu/dspace/bitstream/10419/91247/1/577228374.pdf>. Acesso em: 14 out. 2016.

SHACKELFORD, Douglas A.; SHEVLIN, Terry. Empirical tax research in accounting. Journal of Accounting and Economics, v. 31, n. 1-3, p. 321-387, 2001. DOI: https://doi.org/10.1016/S01654101(01)00021-0.

TANG, TYH. Book-Tax Differences, a Proxy for Earnings Management and Tax Management-Empirical Evidence from China. 2005. In: SSRN. DOI: https://dx.doi.org/10.2139/ssrn.872389

VERGARA, Sylvia Constant. Projetos e Relatórios de Pesquisa em Administração. 13a ed. São Paulo: Atlas, 2011.

WANG, Ying; CAMPBELL, Michael; JOHNSON, Debra. Determinants of Effective Tax Rate of China Publicly Listed Companies. International Management Review, v. 10, n. 1, p. 10, 2014. Disponível em: <http://scholarspress.us/journals/IMR/pdf/IMR-1-2014/v10n1-art-2.pdf>. Acesso em: 28 out. 2016.

ZIMMERMAN, Jerold L. Taxes and firm size. Journal of Accounting and Economics, v. 5, p. 119-149, 1983. https://doi.org/10.1016/0165-4101(83)90008-3

\section{NOTAS}

\section{AGRADECIMENTOS}

Não se aplica.

\section{CONTRIBUIÇÃO DE AUTORIA}

Concepção e elaboração do manuscrito: F.C. Galdi; D.V. Rodrigues

Coleta de dados: D.V. Rodrigues

Análise de dados: D.V. Rodrigues

Discussão dos resultados: F.C. Galdi; D.V. Rodrigues

Revisão e aprovação: F.C. Galdi

\section{CONJUNTO DE DADOS DE PESQUISA}

O conjunto de dados que dá suporte aos resultados deste estudo não está disponível publicamente.

\section{FINANCIAMENTO}

Fernando Caio Galdi agradece ao CNPq pelo financiamento à sua pesquisa.

\section{CONSENTIMENTO DE USO DE IMAGEM}

Não se aplica.

\section{APROVAÇÃO DE COMITÊ DE ÉTICA EM PESQUISA \\ Não se aplica.}

\section{CONFLITO DE INTERESSES}

Não se aplica. 


\section{LICENÇA DE USO}

Os Direitos Autorais para artigos publicados neste periódico são do autor, com direitos de primeira publicação para a Revista. Em virtude de aparecerem nesta Revista de acesso público, os artigos são de uso gratuito, com atribuições próprias, em aplicações educacionais, de exercício profissional e para gestão pública. $\mathrm{A}$ Revista adotou a licença Creative Commons Atribuição 4.0 Internacional - CC BY NC ND. Esta licença permite acessar, baixar (download), copiar, imprimir, compartilhar, reutilizar e distribuir os artigos desde que com a citação da fonte, atribuindo os devidos créditos de autoria. Nesses casos, nenhuma permissão é necessária por parte dos autores ou dos editores. Autores têm autorização para assumir contratos adicionais separadamente, para distribuição não-exclusiva da versão do trabalho publicada nesta revista (ex.: publicar em repositório institucional ou um capítulo de livro).

\section{PUBLISHER}

Universidade Federal de Santa Catarina. Curso de Ciências Contábeis e Programa de Pós-graduação em Contabilidade. Publicação no Portal de Periódicos UFSC. As ideias expressadas neste artigo são de responsabilidade de seus autores, não representando, necessariamente, a opinião dos editores ou da universidade.

\section{EDITORES}

Carlos Eduardo Facin Lavarda e Suliani Rover

\section{HISTÓRICO}

Recebido em: 10/09/2018 - Revisado por pares em: 19/03/2019 - Reformulado em: 24/04/2020 Recomendado para publicação em: 02/05/2020 - Publicado em: 30/05/2020

Uma versão preprint do artigo foi apresentada no Congresso EnANPAD, 2018. 